\title{
Gender inequality and caste: Field experimental evidence from India
}

Discussion Paper no. 2021-07

\section{Asad Islam, Debayan Pakrashi, Soubhagya Sahoo, Liang Choon Wang and Yves Zenou}

\begin{abstract}
:
Using a field experiment in India where patients are randomly assigned to rank among a set of physicians of the same gender but with different castes and years of experience, we show that the differences in patients' physician choices are consistent with gender-based statistical discrimination. Labor market experience cannot easily overcome the discrimination that female doctors suffer. Further, we find that gender discrimination is greater for lower caste doctors, who typically suffer from caste discrimination. Given the increasing share of professionals from a lower caste background, our results suggest that the 'intersectionality' between gender and caste leads to increased gender inequality among professionals in India.
\end{abstract}

Keywords: gender discrimination, statistical discrimination, caste discrimination, intersectionality, affirmative action

JEL Classification: J16, J15, I15, 012

Asad Islam: Centre for Development Economics and Sustainability and Department of Economics, Monash University (email: asadul.islam@monash.edu); Debayan Pakrashi: Department of Economic Sciences, Indian Institute of Technology Kanpur (email: pakrashi@iitk.ac.in); Soubhagya Sahoo: Department of Economic Sciences, Indian Institute of Technology Kanpur (email: ssahoo@iitk.ac.in); Liang Choon Wang: Department of Economics, Monash University (email: liang.c.wang@monash.edu); Yves Zenou: Department of Economics, Monash University (email: yves.zenou@monash.edu).

(C) The authors listed. All rights reserved. No part of this paper may be reproduced in any form, or stored in a retrieval system, without the prior written permission of the author. 


\title{
Gender inequality and caste: Field experimental evidence from India*
}

\author{
Asad Islam^, Debayan Pakrashi, Soubhagya Sahoo*, \\ Liang Choon Wang”, Yves Zenou*
}

\section{September 2021}

\begin{abstract}
Using a field experiment in India where patients are randomly assigned to rank among a set of physicians of the same gender but with different castes and years of experience, we show that the differences in patients' physician choices are consistent with gender-based statistical discrimination. Labor market experience cannot easily overcome the discrimination that female doctors suffer. Further, we find that gender discrimination is greater for lower caste doctors, who typically suffer from caste discrimination. Given the increasing share of professionals from a lower caste background, our results suggest that the 'intersectionality' between gender and caste leads to increased gender inequality among professionals in India.
\end{abstract}

Keywords: gender discrimination; statistical discrimination; caste discrimination; intersectionality; affirmative action.

JEL codes: J16; J15; I15; O12

\footnotetext{
* This research received funding support from the Department of Economics and the Centre for Development Economics and Sustainability (CDES) at Monash University and the Indian Institute of Technology Kanpur. Ethical clearance for the study came from the Institutional Ethics Committee at the Indian Institute of Technology Kanpur (Approval number IITK/IEC/2016-17 II/6). We thank the special issue guest editor Sefa Awaworyi Churchill and two reviewers for helpful comments and suggestions.

- Centre for Development Economics and Sustainability and Department of Economics, Monash University. Email: asadul.islam@monash.edu

\$Department of Economic Sciences, Indian Institute of Technology Kanpur. Email: pakrashi@iitk.ac.in

* Department of Economic Sciences, Indian Institute of Technology Kanpur. Email: ssahoo@iitk.ac.in

• Department of Economics, Monash University. Email: liang.c.wang@monash.edu

- Department of Economics, Monash University. Email: yves.zenou@monash.edu.
} 


\section{Introduction}

Women and ethnic or racial minorities are underrepresented and paid less in a variety of industries and occupations in many countries (Varma, 2018; Fins, 2019; Oostendorp, 2009; Longhi, 2020). Over the past several decades, Affirmative Action (AA), typically implemented in various forms of quotas, has been introduced by many governments to provide or increase access to jobs or seats in educational institutions (Deshpande, 2019). In the case of India, castebased quotas have been implemented in college admissions, public sector jobs, as well as electoral seats in various levels of the government for decades. Although gender quotas have also been used in political representation at all levels of local government since 1993, such quotas for government jobs have only been introduced in a few Indian states and for female college students in science, technology, engineering and math (STEM) fields in recent years. Despite the fact that AA aims at improving the outcomes of marginalized groups, women among marginalized ethnic and racial groups remain considerably more economically disadvantaged and suffer greater inequality than men (Conrad, 2001; Siddique, 2011; Longhi, 2020).

In this paper, we use a field experiment in the state of Uttar Pradesh in India to investigate the relationship between gender inequality and caste. As gender, religion and caste-based discrimination and stigma are particularly prevalent in South Asia; India provides an ideal setting to examine the 'intersectionality' between gender and caste. ${ }^{1}$ We demonstrate theoretically that when patients statistically discriminate doctors based on gender, differential treatment by caste may further widen gender inequality of doctors' outcomes. Our theoretical framework is based on the statistical discrimination theory pioneered by Phelps (1972). Under standard assumptions about gender differences, we first show that statistically discriminatory patients who have a choice between a female and a male doctor with identical years of experience may prefer the male doctor to the female doctor if both doctors are relatively experienced. However, the patients would instead prefer the female doctor to the male doctor if both doctors are relatively inexperienced. These predictions are expected when experience is less informative about the quality of female doctors than the quality of male doctors. When

\footnotetext{
${ }^{1}$ Several studies have documented religion or caste-based gender differentials in India (see, for example, Bhalotra et al., 2010; Borooah and Iyer, 2005). Islam et al. (2021) document that Muslims in India are perceived by Hindu as responsible for the spread of COVID-19. Delavande and Zafar (2013) find evidence of discriminatory behavior against females among religious institution students in Pakistan. Begum et al. (2018) document evidence consistent with gender bias in the labor market in Bangladesh while Abbink et al. (2020) document gender bias exists within households in Bangladesh.
} 
there is also caste discrimination against lower caste doctors, the disadvantage that experienced low-caste female doctors suffer increases while the advantage that inexperienced low-caste female doctors enjoy diminishes. Thus, when caste discrimination and gender discrimination coexist, gender inequality exacerbates among lower caste doctors relative to upper caste doctors.

We use data collected from a field experiment to test: (i) whether patients statistically gender discriminate against doctors; and (ii) whether discrimination-induced gender inequality is indeed greater for low-caste doctors who also suffer from caste discrimination. The field experiment includes 3,128 adult participants with demographic and social-economic characteristics similar to those of the adult population in the state of Uttar Pradesh (Islam et al., 2018). The participants were invited to register for an upcoming free-of-charge health check offered by a mobile clinic. At the point of registration, the participants were randomly assigned to express their preferences either among four male doctors or four female doctors. The four doctors are from either a high or low-caste background and either a high-level or low-level of experience.

As the field experiment uses a correspondence method to elicit preference rankings, characteristics of doctors that correspond to the features of the theoretical model are fully controlled for. As a result, we are able to make inferences without the threats of confounding unobservables from which typical audit and observational studies of discrimination may suffer. More importantly, because participants were randomly assigned to choose either among all male doctors or all female doctors, we can attribute the mean differences in rankings of doctors of different genders by experience level and caste group as evidence of discrimination.

We find that participants in the experiment discriminate doctors in a manner consistent with statistical discrimination based on gender. Male doctors with a high level of experience are more preferred than female doctors with the same level of experience on average, but the opposite is true for doctors with a low level of experience. Thus, it is difficult for female doctors to overcome the relative disadvantage they suffer even as they accumulate more labor market experience. We also find evidence of caste discrimination against low-caste doctors at all levels of experience. When we focus on high-caste doctors, female doctors are more preferred than male doctors when they have similarly low level of experience, but both genders are equally preferred when they have similarly high level of experience. In contrast, when we focus on 
low-caste doctors, male doctors and female doctors are equally preferred when they have similarly low level of experience, but male doctors are more preferred than female doctors when they have similarly high level of experience. Thus, gender discrimination and inequality are worse among low-caste doctors, confirming the theoretical predictions. The findings also imply that with the rising share of professionals coming from a lower caste background as a result of caste-based reservations, gender inequality is expected to rise among professionals in India. The evidence of gender and caste discrimination implies potentially significant negative effects on the general health of the population. Specifically, the undesirable labor market consequences for women and low-caste individuals may discourage them from pursuing a medical career in the first place or from staying in the medical profession in the longer term. This decreased supply of medical professionals can lower competition in the healthcare market, which in turn reduces the quality of healthcare and the health of the population.

This paper contributes to the literature on gender inequality and discrimination in a number of ways. First, it adds to the growing evidence that gender inequality can be explained by various forms of gender-based statistical discrimination (see e.g., Castillo et al., 2013 and Bohren et al., 2019). Second, it advances the research on intersectionality pioneered by Crenshaw (1989; $1991)^{2}$ by using the statistical discrimination framework to show how one marginalization dimension may worsen outcomes of another marginalization dimension of individuals and shed light on the relationship between intersectionality and gender inequality.

The research on intersectionality and the relationship between gender inequality and caste, especially in the context of India, is relatively scant. Cassan (2019) shows empirically that AA for Scheduled Castes in education increases their educational attainment, especially in literacy and secondary schooling, but the benefits flow mainly to men, but not to low-caste women. Karekurve-Ramachandra and Lee (2020) show that gender quotas worsen the representation of low-caste politicians in India. We help advance this area of research by using the statistical discrimination framework to offer insights into how gender inequality may widen among lowcaste individuals when they also suffer from caste discrimination. As prior economics research on the unintended consequences of AA typically utilizes the statistical discrimination framework, our findings suggest the usefulness of statistical discrimination theories in

\footnotetext{
2 The term "intersectionality" was coined in 1989 by Kimberlé Crenshaw to describe how race, class, gender, and other marginalized aspects of individual characteristics "intersect" with one another and overlap.
} 
understanding the interconnection between intersectionality, AA, and underrepresentation. ${ }^{3}$ Importantly, because the representation of lower-caste professionals, especially among the younger generation, has increased significantly in various sectors over time due to the use of caste-based AA, the findings imply that gender inequality is expected to increase among professionals in India. The findings highlight the importance of having appropriate policies focusing on the intersection of different discriminated groups and addressing the cumulative effects of discrimination on them.

\section{Institutional background}

\subsection{Gender inequality and gender-based affirmative action (AA) in India}

India ranked 122 out of 162 countries on the 2018 gender inequality index (UNDP, 2019). India is characterized by low female labor force participation rates and high gender wage gaps. Women's labor force participation rate in India is only around a quarter in rural areas and below 20 percent in urban areas, whereas the world average is around half (Lahoti and Swaminathan, 2016). Female workers only earned roughly 65 percent of what male workers earned on average in the year 2018-2019 in India (Chakraborty, 2020).

The Indian government has taken a number of steps to address gender inequality, especially in the political representation of women. For example, a constitutional amendment enacted in 1993 requires the reservation of one third of all levels of local government electoral seats in India for women. Numerous studies have looked at how these female political reservations affect the outcomes of women politicians and electorates in India (see, e.g., Chattopadhyay and Duflo, 2004; Beaman et al., 2012; Clots-Figueras, 2012; Gangadharan et al., 2016; Afridi et al., 2017; Maitra and Rosenblum, 2021). In general, these studies show that the gender quotas help improve the outcomes of women.

There has not been any constitutional mandate or laws for the reservation of seats for women in public-sector jobs or education institutions in India. Nonetheless, a small number of states, such as Bihar, Gujarat, Madhya Pradesh, and Punjab, have in the past 10 years introduced reservations for women in government jobs (Kumar, 2020). In light of the low level of female

\footnotetext{
${ }^{3}$ The literature studying the unintended consequences of AA under statistical discrimination dated back to the seminal work of Coate and Loury (1993). See Arcidiacono and Lovenheim (2016) for general overviews of the pros and cons of AA policies. Balafoutas et al. (2016) and Leibbrandt et al. (2018) document some unintended consequences of gender quotas.
} 
participation in STEM fields, the government also introduced a quota for women in the Indian Institute of Technology (IITs) in 2018 (Sharma, 2020). In the first year of implementation, 2018-19, 14 per cent of seats were added for women. The number went up to 17 per cent in 2019-20 and 20 per cent in 2020-21.

\subsection{The caste system and caste-based AA policy}

The caste system played an important role in ancient Hindu tradition and caste dictated almost every aspect of Hindu religious and social life in India for centuries. It divides Hindus into four main hierarchies - Brahmins, Kshatriyas, Vaishyas, and Shudras. At the top of the hierarchy are Brahmins, who were priests and intellectuals. The second category is the Kshatriyas, who were rulers and aristocrats of the society. The third category is Vaishyas, who were traders, landlords, farmers, and merchants. The Shudras, who were peasants and working class of the society, lied at the bottom. Below these four groups are the Dalits or the untouchables, who worked in degrading jobs. The first three castes were classified as the upper caste. The upper caste had social and economic rights that the lower caste Shudras and Dalits did not have. These days the lower caste groups are listed in three categories: (1) Scheduled Castes (SCs) who were untouchables; (2) Scheduled Tribes (STs); and (3) Other Backward Classes (OBCs), which include Shudras.

Although the influence of caste has declined in recent decades, caste identities remain strong, and surnames are almost always indications to which caste a person belongs. There is also evidence suggesting that the lower caste groups continue to face discrimination and stigmatization (Madheswaran and Attewell, 2007; Thorat and Attewell, 2007; Siddique, 2011; Banerjee et al., 2009; Banerjee et al., 2013; Islam et al., 2018; Islam et al., 2021). Findings from studies such as Siddique (2011), Wankhede (2016), and Chaudhury and Sinha (2020), indicate that the extent of gender inequality is worse for low-caste groups than for high-caste groups.

Caste-based reservation policy in India was launched in 1950 to promote equal opportunities for SCs and STs in areas of public-sector employment, education, and politics (Deshpande, 2013). After the Mandal Commission's recommendations, public-sector employment quotas were further extended to OBCs in the early 1990s. In 2006, educational quotas for OBCs were established through the $93^{\text {rd }}$ constitutional amendment. Government-funded universities and colleges allot seats according to caste-based quotas, which give 7.5 percent to STs, 15 percent 
to SCs, and 27 percent to OBCs (Deshpande, 2013). In order to meet these quotas, the qualifying scores for admission are typically set differently across caste groups. For example, Bertrand et al. (2010) document that among all students applying to an engineering college, the qualifying scores for admission were roughly 480 out of a possible 900 for upper caste applicants, 419 for OBC applicants, and 182 for SC applicants. This gradation of entrance scores by caste is also documented in Bagde et al. (2011) for a sample of 214 engineering colleges. The reservation policy has resulted in an increasing share of tertiary students enrolled in various medical science programs to come from a lower caste background, especially so for OBC (see Figure 1).

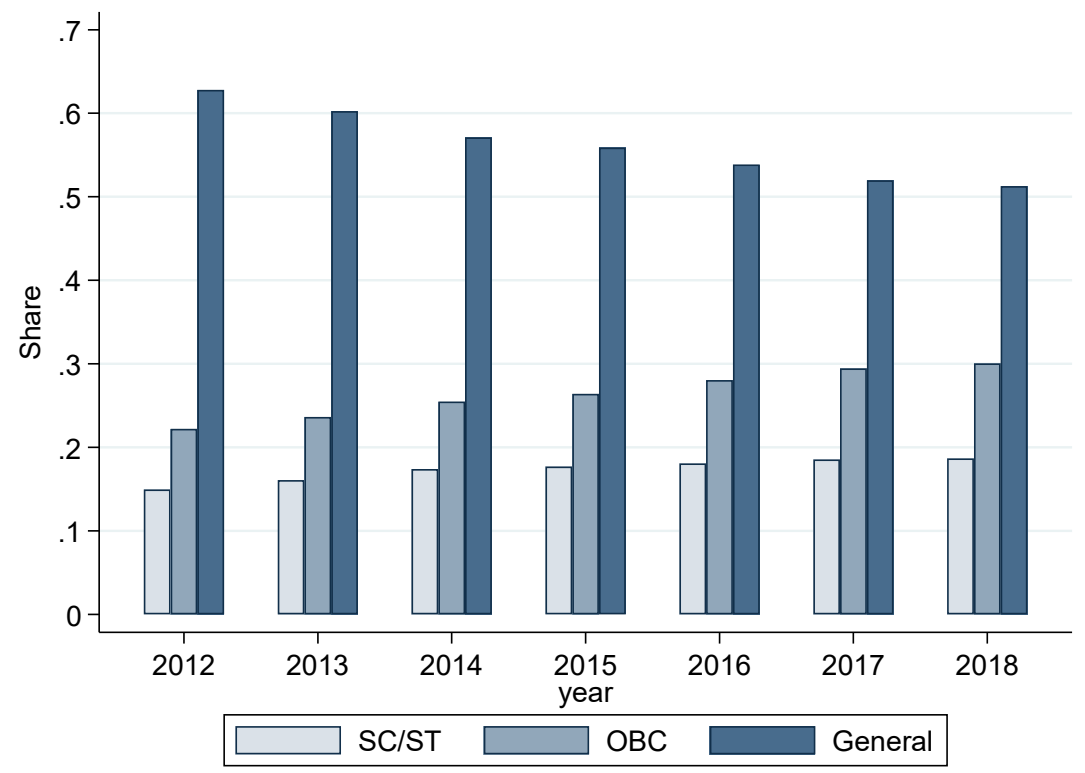

Figure 1. Share of tertiary students enrolled in medical sciences by caste and year.

Notes: Authors' calculation based on data drawn from the All India Survey of Higher Education (AISHE). The data include tertiary students enrolled in all medical science programs (e.g., MBBS, pharmacy and pharmacology, nursing, etc.).

\section{Theory and predictions}

\subsection{Gender-based statistical discrimination}

Statistical discrimination theory pioneered by Phelps (1972) and Arrow (1973) posits that in the absence of direct information about quality or productivity, individuals would use beliefs about group identities and other signals of quality or productivity to make inferences about the unobserved quality or productivity. Following Aigner and Cain (1977), we present a simple model of statistical discrimination to highlight how patients may discriminate doctors on the basis of gender and to draw predictions that we test in the field experiment. 
The experience, $x$, of a doctor of gender type, $s$, provides gender-based statistical discriminatory patients a signal of the doctor's quality, $q$, with an error (noise), $\epsilon$ :

$$
x_{s}=q_{s}+\epsilon_{s}
$$

where $\epsilon_{s} \sim N\left(0, \sigma_{\epsilon, S}^{2}\right), q_{s} \sim N\left(\beta_{s}, \sigma_{q, S}^{2}\right)$, and $\operatorname{cov}\left(q_{s}, \epsilon_{s}\right)=0$. It follows that $E\left(x_{s}\right)=\beta_{s}$ and $\operatorname{var}\left(x_{s}\right)=\sigma_{q, s}^{2}+\sigma_{\epsilon, s}^{2}$.

Each patient's decision problem is first to forecast the expected value of the doctor quality, $q$, from the noisy signal, $x$, on the basis of the doctor's gender, $s$. After forming the expected quality of each doctor, $E(q \mid x, s) \equiv \hat{q}_{x, s}$, the patient can then rank the available doctors accordingly. Following Phelps (1972) and Ewens et al. (2014), a patient uses the sample of doctors they have encountered to estimate $\gamma_{s}$ and $\beta_{s}$ for each gender type $s=\{f, m\}$ via the Ordinary Least Squares estimator and obtain the following plug-in equation:

$$
\hat{q}_{x, s}=\left(1-\gamma_{s}\right) \beta_{s}+\gamma_{s} x_{s},
$$

where $\gamma_{s}=\frac{\operatorname{cov}\left(q_{s}, x_{s}\right)}{\operatorname{var}\left(x_{s}\right)}$. Note that Phelps (1972) assumes that each patient has previously encountered a large independently and identically distributed sample of individuals (doctors) in each group, while Ewens et al. (2014) allows the sample of individuals to be correlated and small (i.e., non-representative or biased sampling). Recently, using data on responses of experimental subjects observed over time, Bohren et al. (2019) demonstrate that these estimates (beliefs) can be biased. Since the field experimental data that we have are cross-sectional and we do not observe the history of each patient's encounters with different doctors, we are agnostic as to whether the individuals update their beliefs and the beliefs are biased or not. Note that we can potentially include an intercept term in equation (1) to allow for bias, but it has no bearing on $\gamma_{s}$, which is the focus here.

To predict the quality of a newly encountered doctor, the patient plugs in $x_{s}$ using equation (2) to obtain $\hat{q}_{x, s}$. The numerator $\operatorname{cov}\left(q_{s}, x_{s}\right)$ of $\gamma_{s}$ is $\sigma_{q, s}^{2}$ given equation (1), and it is positive as equation (1) specifies that experience provides positive signal of quality. In reality, $\operatorname{cov}\left(q_{s}, x_{s}\right)$ can be negative as it depends on the sample of doctors the patient previously encountered (Ewens et al., 2014; Islam et al., 2018). As we are interested in predictions on average, we hypothesize that $\operatorname{cov}\left(q_{s}, x_{s}\right)>0$ for the average patient. The denominator $\operatorname{var}\left(x_{s}\right)$ of $\gamma_{s}$ is the sum of $\sigma_{q, s}^{2}$ and $\sigma_{\epsilon, s}^{2}$. 
To explain the discrimination from which highly skilled female workers suffer in the labor market, the labor economics literature typically assumes that $\sigma_{\epsilon, f}^{2}>\sigma_{\epsilon, m}^{2}$, while maintaining that $\beta_{m}=\beta_{f}=\beta$ and $\sigma_{q, f}^{2}=\sigma_{q, m}^{2}$ (e.g., see Aigner and Cain, 1977). The assumption that $\sigma_{\epsilon, f}^{2}>\sigma_{\epsilon, m}^{2}$ corresponds to the notion that signal is a less reliable indicator of quality for female workers than for male workers. It is typically argued in the labor market context that employers find it more difficulty in assessing the quality of female workers based on their observable characteristics (Lesner, 2018). Ewens et al. (2014) show that the observed sample of individuals can give the estimates that $\sigma_{\epsilon, f}^{2}>\sigma_{\epsilon, m}^{2}$ when signals of individuals in the sample are positively correlated and the sample size is smaller for $f$ than $m$. We follow these studies and assume that $\sigma_{\epsilon, f}^{2}>\sigma_{\epsilon, m}^{2}$, which means that experience is less informative about the quality of female doctors than the quality of male doctors. Given these assumptions and equations (1) and (2), we have:

$$
0<\gamma_{f}<\gamma_{m}<1
$$

Proposition 1. Given the assumptions made for equations (1) and (2) and inequality (3), there exists a value of experience $x^{*}=\beta$ for which $\hat{q}_{x^{*}, m}=\hat{q}_{x^{*}, f}$. For $x>x^{*}, \hat{q}_{x, m}>\hat{q}_{x, f}$ and for $x<x^{*}, \hat{q}_{x, m}<\hat{q}_{x, f}$.

Proof. Solving $\left(1-\gamma_{m}\right) \beta+\gamma_{m} x^{*}=\left(1-\gamma_{f}\right) \beta+\gamma_{f} x^{*}$ yields $x^{*}=\beta$. Given that $x^{*}=\beta$, when $\hat{q}_{x, m}>\hat{q}_{x, f}$, we have $\left(1-\gamma_{m}\right) x^{*}+\gamma_{m} x>\left(1-\gamma_{f}\right) x^{*}+\gamma_{f} x$. The solution yields $x>$ $x^{*}$. Similarly, when $\hat{q}_{x, m}<\hat{q}_{x, f}$, the solution yields $x<x^{*}$.

Proposition 1 implies that male doctors are more preferred than female doctors at a high level of experience, whereas female doctors are more preferred than male doctors at a low level of experience. Note that this situation is unique to statistical discrimination. Islam et al. (2018) show that this situation cannot arise under taste-based discrimination when preferences satisfy several fundamental axioms. Following Becker's (1957) notion of distaste, the online appendix uses an example to illustrate why taste-based discrimination cannot generate this prediction.

It is possible that $\beta_{m} \neq \beta_{f}$ in reality. Note that even if $\beta_{m}>\beta_{f}$ instead of $\beta_{m}=\beta_{f}=\beta$ as we have assumed, there still exists a value of experience $x^{*}$ at which $\hat{q}_{x^{*}, m}=\hat{q}_{x^{*}, f}$, but the value that $x^{*}$ takes will become $\frac{\left(1-\gamma_{m}\right) \beta_{m}-\left(1-\gamma_{f}\right) \beta_{f}}{\gamma_{f}-\gamma_{m}}$. Similarly, it is possible that $\sigma_{q, f}^{2}>\sigma_{q, m}^{2}$ in 
reality. As long as the extent to which $\sigma_{\epsilon, f}^{2}>\sigma_{\epsilon, m}^{2}$ is relatively greater than the extent to which $\sigma_{q, f}^{2}>\sigma_{q, m}^{2}$, inequality (3) will hold. Without data on actual quality, the assumptions that $\beta_{m}=$ $\beta_{f}=\beta$ and $\sigma_{q, f}^{2}=\sigma_{q, m}^{2}$ suffice. More importantly, if the empirical evidence is consistent with inequality (3), then these assumptions are reasonable.

\subsection{Preliminary assessment of the theoretical assumptions}

We first use publicly available data from India to provide some preliminary assessment of the key feature of the gender-based statistical discrimination model: greater return to experience is for male doctors than female doctors.

Table 1

Gender differences in the weekly earnings of medical professionals.

\begin{tabular}{lccccc}
\hline & $(1)$ & $(2)$ & $(3)$ & $(4)$ & $(5)$ \\
& Male & Male & Female & Female & All \\
\hline Experience & $84.11^{*}$ & $86.19^{* * *}$ & 73.91 & 11.19 & 8.96 \\
& $(43.60)$ & $(25.88)$ & $(74.76)$ & $(30.59)$ & $(32.55)$ \\
Male $\times$ Experience & & & & & $76.12^{*}$ \\
Male & & & & & $(44.51)$ \\
& & & & & $-601.70^{* *}$ \\
Controls & No & Yes & No & Yes & Yes \\
Observations & 325 & 325 & 84 & 84 & 409 \\
\hline
\end{tabular}

Notes: Sampling weights are used. The occupations included in the sample are physicians and surgeons, dental surgeons, veterinarians, pharmacists, dieticians and nutritionists, and public health physicians. The sample is restricted to those aged 25 to 39 . Experience is age minus 23. Additional control variables include wage employee dummy, urban status, and a set of occupation fixed effects.

Source: The 2004 Employment Survey (Socio-Economic Survey, Household Schedule 10: Employment and Unemployment) was collected by the National Sample Survey Organization (NSSO). We obtained the data from Minnesota Population Center's (2020) Integrated Public Use Microdata Series.

The most recent publicly available data that may allow for such a preliminary investigation is the 2004 Employment Survey as it contains information about the weekly earnings of medical professionals in addition to other important demographic characteristics. Using earnings as a proxy for quality of healthcare of a doctor, we find that the return to experience is indeed greater for male medical professionals than female medical professionals in India. In particular, Table 1 shows that the return to experience is significantly positive for male medical professionals (columns (1) and (2)), but not statistically different from zero for female medical professionals (columns (3) and (4)). Given the greater return to experience for male than female, the intercept term is lower for male than female (column 5). As we also assume that the mean quality of healthcare is identical by gender in the model, we also check whether the earnings data are 
consistent. Indeed, we cannot reject the null hypothesis that mean earnings is similar between male and female medical professionals in the range of experience that we focus on $(p=0.928)$. Thus, the observational data are consistent with the key assumptions of the statistical discrimination model. Since observational data are generally susceptible to various confounds due to unobservables, our focus in this paper is to examine the predictions of the model using field experimental data.

\subsection{Caste discrimination and gender inequality}

When there is caste discrimination, it is possible for patients to expect the mean quality of lowcaste $(L)$ doctors to be lower than the mean quality of high-caste $(H)$ doctors on average, so that: $\beta_{L}<\beta_{H}$ (Islam et al., 2018).

Proposition 2. With caste discrimination against low-caste doctors, the experience level above which the predicted quality is greater for male doctors than for female doctors would occur is at a lower point for low-caste doctors than high-caste doctors: $x_{L}^{*}<x_{H}^{*}$.

Proof. At $x_{c}^{*}$, the condition $\left(1-\gamma_{m, c}\right) \beta_{c}+\gamma_{m, c} x_{c}^{*}=\left(1-\gamma_{f, c}\right) \beta_{c}+\gamma_{f, c} x_{c}^{*}$ holds for each of caste group $c=\{L, H\}$. The solution yields $x_{c}^{*}=\beta_{c}$. Because $\beta_{L}<\beta_{H}$, we have $x_{L}^{*}<x_{H}^{*}$.

Corollary 1. Given the range of experience where $0 \leq x_{L}^{*}<x_{H}^{*}$, the mean male-female predicted quality difference is larger for low-caste doctors than for high-caste doctors. That is, $\operatorname{Gap}_{L}>\operatorname{Gap}_{H}$, where

$$
\begin{aligned}
\operatorname{Gap}_{L} & \equiv \int_{\hat{q}_{0, m}^{L}}^{\infty} \hat{q}_{x, m}^{L} f\left(\hat{q}_{x, m}^{L}\right) d \hat{q}_{x, m}^{L}-\int_{\hat{q}_{0, f}^{L}}^{\infty} \hat{q}_{x, f}^{L} f\left(\hat{q}_{x, f}^{L}\right) d \hat{q}_{x, f}^{L}, \text { and } \\
\operatorname{Gap}_{H} & \equiv \int_{\hat{q}_{0, m}^{H}}^{\infty} \hat{q}_{x, m}^{H} f\left(\hat{q}_{x, m}^{H}\right) d \hat{q}^{H}{ }_{x, m}-\int_{\hat{q}_{0, f}^{H}}^{\infty} \hat{q}_{x, f}^{H} f\left(\hat{q}^{H}{ }_{x, f}\right) d \hat{q}^{H}{ }_{x, f}
\end{aligned}
$$

Note that $\hat{q}_{0, s}^{c}$ is the predicted quality for doctor of caste $c$ and gender $s$ at $x=0$ and $f(\cdot)$ denotes the probability density function of $\hat{q}_{0, s}^{c}$.

Figure 2 illustrates the relationship between the predicted quality (y-axis) and experience level (x-axis) of doctor by the gender of doctor. Figure 2A shows that the predicted quality increases with experience at a higher rate for male doctors (dashed line) than female doctors (solid line). This feature is driven by the standard assumption that the reliability of signal (i.e., how informative experience is about a doctor's quality) is lower among female doctors than among male doctors. When $x<x^{*}$, the predicted quality is greater for female doctors than for male 
doctors. When $x>x^{*}$, the predicted quality is greater for male doctors than female doctors. Basically, the noisy (unreliable) signal benefits female doctors more when they are less experienced because patients infer their quality more from the mean quality of all female doctors than their noisy signal. At $x=x^{*}$, the predicted quality is identical for both male and female doctors. Figure $2 \mathrm{~B}$ shows that with caste discrimination, for $x>0$, the range of experience levels at which the predicted quality is greater for low-caste male doctors than lowcaste female doctors become larger relative to Figure 2A. Figure 2C shows that with caste discrimination, for $x>0$, the range of experience levels at which the predicted quality is greater for high-caste male doctors than low-caste female doctors become smaller relative to Figure 2A. The differences between Figure 2B and Figure 2C are jointly driven by: (1) the expected quality of doctors being lower for low-caste doctors than high-caste doctors (as a result of the lower mean test scores among low-caste students); and (2) the lower return to experience for female doctors. Thus, male-female gap in predicted quality is greater among low-caste doctors than high-caste doctors.

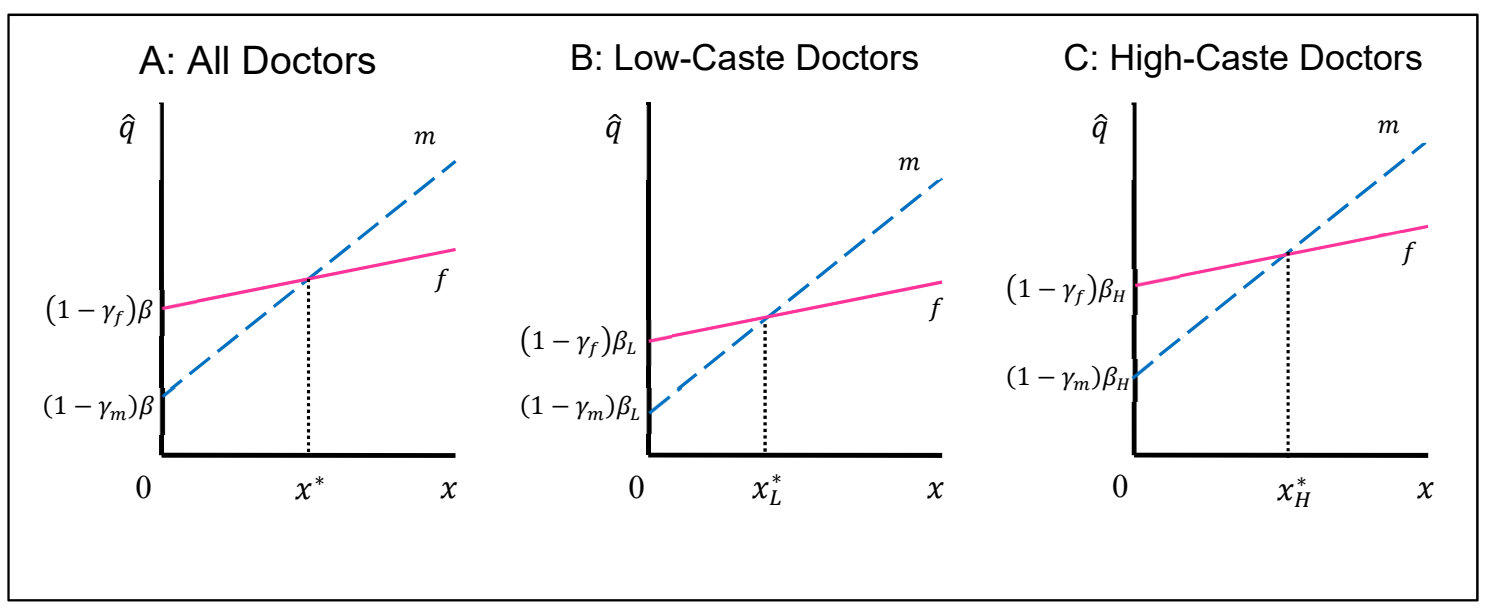

Figure 2. The relationship between predicted quality and experience of doctor.

\section{Field Experiment}

We use data drawn from a randomized controlled experiment in the field to test the predictions of the gender-based statistical discrimination model. The field experiment was conducted in the Kanpur Nagar district of Uttar Pradesh (UP) state, India. UP, one of the most populous state in India, has the largest concentration of lower-caste population. Note that the field experiment was originally conducted by Islam et al. (2018) to examine the sources of caste-based 
discrimination. ${ }^{4}$ Here, we focus on the genders of doctors to test for gender-based discrimination and its relationship with gender inequality and caste discrimination.

\subsection{Sample and participants}

The field experiment took place in 40 areas across the Kanpur Nagar district between August and October 2017. These locations were selected because their average demographic and social economic characteristics were similar to the averages of UP state. A total of 3,128 adults participated in the field experiment. Table 2 shows that the average demographic and social economic characteristics of the participants are indeed similar to those in UP state.

Table 2

Descriptive Statistics.

\begin{tabular}{lccc}
\hline & Uttar Pradesh & \multicolumn{2}{c}{ Experimental Sample } \\
& Mean & Mean & Std. Dev. \\
\hline Male & 0.51 & 0.51 & 0.50 \\
Age & 38.0 & 37.8 & 14.3 \\
High caste & 0.27 & 0.27 & 0.44 \\
Hindu & 0.80 & 0.80 & 0.40 \\
College educated & 0.08 & 0.11 & 0.32 \\
Below poverty line & 0.29 & 0.34 & 0.47 \\
Urban resident & 0.34 & 0.34 & 0.48 \\
\hline
\end{tabular}

Notes: The field experiment sample include 3,128 participants. All statistics for Uttar Pradesh were sourced from NSS $68^{\text {th }}$ Round, 2011-2012, except the below poverty line figure which came from World Bank (2016).

\subsection{Experimental design and procedures}

The experiment involved several stages. In Stage 1, participants registered interests and expressed their preferences among four different doctors presented to them. In Stage 2, participants answered a short demographic and social economic survey questionnaire. In Stage 3, participants were assigned doctors and appointments. In Stage 4, participants received healthcare services.

In Stage 1, experimenters advertised to households in each sampled area about an upcoming free-of-charge health check service offered by a mobile clinic. Participants were invited to register their interests for a regular health check and express preference among four different doctors presented to them.

\footnotetext{
${ }^{4}$ Islam et al. (2018) theoretically distinguish the predictions of taste-based discrimination from the predictions of statistical discrimination (as the predictions of these two main theories of discrimination are often identical) and devise a method to bound the extent of taste-based discrimination. They then use the field experimental data to quantify the extent of taste-based discrimination.
} 
At the point of registration, participants were instructed to rank four doctors from their most preferred (rank 1) to their least preferred (rank 4), without the possibility of an equal rank, on a sign-up sheet. The sign-up sheet contains a two-by-two matrix containing the names and experience levels of the four doctors of the same gender. Participants were randomly assigned to either a female-doctor treatment group or a male-doctor treatment group. The order in which a doctor appeared was also randomized. To ensure that the rankings were incentive compatible, participants were informed that they were more likely to be assigned the more preferred doctor than the less preferred doctor. When we present the results, we focus on using the reverse rank, which is five minus the rank received, as well as whether a doctor is ranked as the most preferred, as the outcome measures. Using the indicator for first-ranked doctor as an alternative outcome measure allows us to check whether the results are sensitive to the presence of patients who do not truthfully report their preferences for the less preferred doctors.

There are several reasons why participants were not allowed to rank doctors equally. First, it is impossible to elicit true indifference because choosing one doctor over another is fully consistent with indifference between the two doctors. In other words, a person may randomly choose one of the two doctors when the person is indifferent between the two doctors. Second, by forcing participants to give strict ranking, participants with weak preferences could not give equal ranking out of social desirability concerns. Third, as long as we are able to detect treatment differences, any measurement errors due to indifferences are differenced out on average.

The four doctors are: (1) a doctor with a high-caste surname and a high level of experience; (2) a doctor with a low-caste surname and a high level of experience; (3) a doctor with a high-caste surname and a low level of experience; and (4) a doctor with a low-caste surname and a low level of experience. The high-caste surname belongs to the general-category (GC) caste. The low-caste surname belongs to either a schedule-caste (SC), schedule-tribe (ST), or otherbackward-class (OBC) group, but never both. The high level of experience is either 12 years or eight years of experience but never both, whereas the low level of experience is always four years. The first name of the doctor was not disclosed, but only the initial. ${ }^{5}$

\footnotetext{
${ }^{5}$ The high-caste surnames used are Bajpai, Dixit, Mishra, and Pandey. The low-caste surnames used are Katiyar, Pal, Rajput, Yadav, Kanaujiya, Kureel, Sonkar, and Valmiki.
} 
Once participants' rankings of the four doctors were elicited, they filled out a short demographic and social economic survey questionnaire in Stage 2. The survey collected information about their age, gender, caste identity, education level, religious affiliation, and so on. The field experiment concluded by the end of Stage 2 .

In Stage 3, participants were informed about the doctor they were assigned to and the location and time of their upcoming health-check appointment. In Stage 4, the mobile clinic arrived in the area to deliver service. The mobile clinic delivered the service within one week of registration.

Table 3

Balance tests.

\begin{tabular}{lccc}
\hline & \multicolumn{2}{c}{ Doctor Treatment Group } & Group \\
& Female & Male & Difference \\
\hline Male & 0.513 & 0.502 & -0.012 \\
& $(0.013)$ & $(0.013)$ & $(0.018)$ \\
Age & 37.850 & 37.770 & -0.080 \\
General caste & $(0.365)$ & $(0.356)$ & $(0.510)$ \\
Married & 0.266 & 0.268 & 0.002 \\
& $(0.011)$ & $(0.011)$ & $(0.016)$ \\
Hindu & 0.834 & 0.828 & -0.006 \\
& $(0.009)$ & $(0.010)$ & $(0.013)$ \\
College educated & 0.814 & 0.784 & $-0.030^{* *}$ \\
& $(0.010)$ & $(0.010)$ & $(0.014)$ \\
Employed & 0.117 & 0.112 & -0.006 \\
Below poverty line & $(0.008)$ & $(0.008)$ & $(0.011)$ \\
\multirow{2}{*}{ Urban } & 0.442 & 0.438 & -0.004 \\
& $(0.013)$ & $(0.013)$ & $(0.018)$ \\
Experience is 4 vs 12 years & 0.343 & 0.339 & -0.004 \\
& $(0.012)$ & $(0.012)$ & $(0.017)$ \\
& 0.347 & 0.343 & -0.003 \\
Notes: The & $(0.012)$ & $(0.012)$ & $(0.017)$ \\
\end{tabular}

Notes: The sample size is 3,128 participants; 1,561 are in the female-doctor treatment group while 1,567 are in the male-doctor treatment group. Robust standard errors are reported in parentheses. $* * * \mathrm{p}<0.01 ; * * \mathrm{p}<0.05 ; * \mathrm{p}<0.1$.

\subsection{Verification of randomization}

Patients were randomly assigned to either the female-doctor treatment group or male-doctor treatment group. Table 3 reports the balance tests by treatment group. Apart from Hindu religion, the characteristics of patients who see male doctors are statistically similar to the characteristics of patients who see female doctors. The statistically significant difference in 
religious affiliation between the two groups are expected to occur by chance given that the treatment was randomized at the point when the large sample of participants were contacted. More importantly, our results are robust to controlling for the difference in religious affiliation.

\section{Results}

In this section, we report the field experimental results. First, we report evidence that the overall mean ranking of doctors is consistent with the model that patients statistically discriminate against doctors of different genders. Second, we report evidence that gender inequality in doctors' outcomes is greater among low-caste doctors, who also suffer from caste discrimination.

\subsection{Gender-based statistical discrimination}

According to inequality (3) in Section 3.1, we expect the return to experience for female doctors, $\gamma_{f}$, to be lower than that for male doctors, $\gamma_{m}$, if patients statistically discriminate doctors by gender. Figure 3 confirms that inequality (3) holds in the field experiment by plotting the mean reverse rank of a doctor against the doctor's experience by gender of the doctor. Note that the reverse rank is five minus the rank the doctor receives from a patient. For doctors with a low level of experience, female doctors are on average more preferred than male doctors. For doctors with a high level of experience, male doctors are on average more preferred than female doctors. Figure 3 also indicates that $x^{*}$, where the expected quality of male doctors equals the expected quality of female doctors in Proposition 1, occurs between the low level of experience and the high level of experience that patients were presented.

The regression estimates reported in Table 4 confirm the patterns shown in Figure 3. Table 4 reports the estimates based on regression specifications when we use the reverse rank of a doctor as the dependent variable (columns (1) to (3)). The specification in column (1) does not include additional patient's or doctor's control variables, whereas the specifications in columns (2) and (3) include additional patient's and doctor's controls. Column (1) shows that female doctors with a low level of experience receive a reverse rank of 1.8 on average. In comparison, male doctors with a low level of experience receive a reverse rank of 1.3 on average, and the average difference of -0.5 in reverse rank is statistically significant $(p<0.01)$. For female doctors with a higher level of experience, their reverse rank increases significantly by approximately 1.3 on average. For male doctors with a high level of experience, their reverse 
rank increases significantly by approximately 1.4 on average. As experienced doctors are more preferred by the participants, the results indicate that doctor's experience signals better quality, which is consistent with equations (1) and (2) in Section 3.1. Once we include additional controls, the return to experience becomes larger for female doctors, while the difference in the return to experience between female and male doctors fall slightly. The statistically and significantly greater return to experience for male doctors than female doctors, as measured by the difference in reverse rank that is between 0.08 to 0.1 , confirms inequality (3) of the genderbased statistical discrimination model.

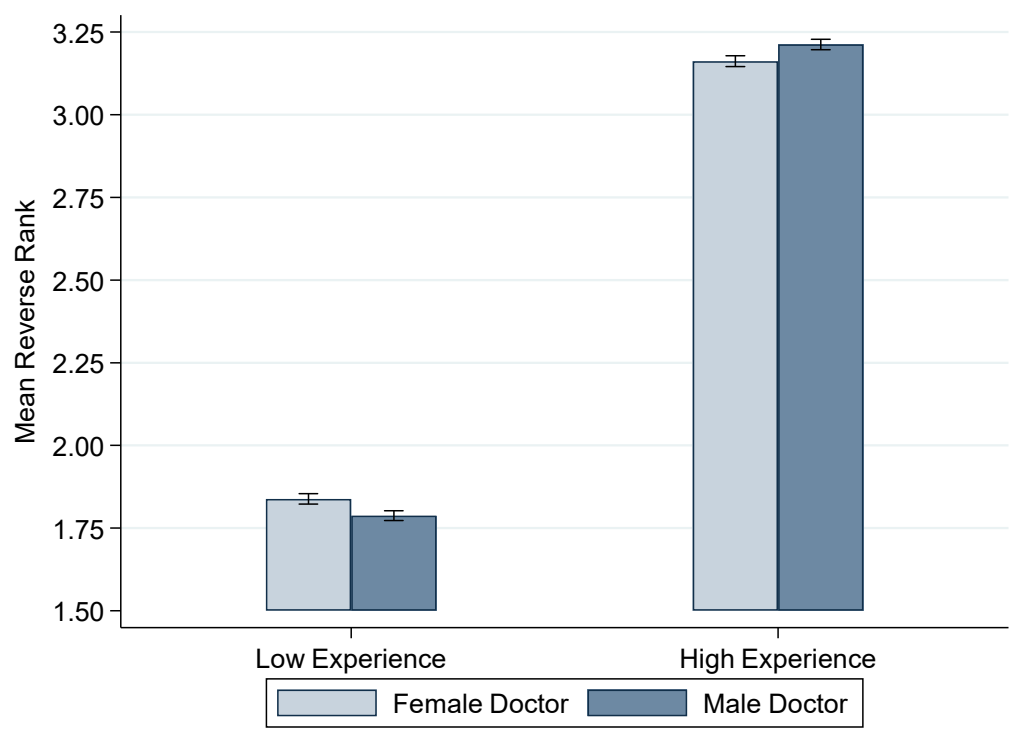

Figure 3. Statistical discrimination of doctors based on gender.

Notes: Reverse rank is five minus the rank of a doctor receives from a participant. A doctor who receives a higher reverse rank is more preferred. Error bars represent mean \pm SEM.

Table 4 also reports the estimates based on linear probability models where the dependent variable is the dummy for whether a doctor is ranked the most preferred (columns (4) to (6)). The results are similar to those using reverse rank as the dependent variable. Only about 7 percent of low-experience female doctors are the most preferred (column (1)). Low-experience male doctors are 2 percentage-point less likely to be ranked first than low-experience female doctors. Doctors with more years of experience are more likely to be ranked first. In particular, about 44 percent of high-experience female doctors are the most preferred and about 46 percent of high-experience male doctors are the most preferred (column (1)). In terms of being the most preferred, the return to experience is about 4 percentage-point greater for male doctors than female doctors. Similar to the estimates based on reverse ranks, when we include additional 
controls, the return to experience for female doctors become larger while the difference in the return to experience between female and male doctors falls slightly.

Table 4

Gender gap in doctor preferences by experience of doctor.

\begin{tabular}{|c|c|c|c|c|c|c|}
\hline & (1) & (2) & (3) & (4) & (5) & (6) \\
\hline & \multicolumn{3}{|c|}{------ Reverse rank ------ } & \multicolumn{3}{|c|}{------ Ranked first ------ } \\
\hline Male doctor & $\begin{array}{l}-0.051 * * * \\
(0.018)\end{array}$ & $\begin{array}{l}-0.044 * * \\
(0.018)\end{array}$ & $\begin{array}{l}-0.045^{* *} \\
(0.018)\end{array}$ & $\begin{array}{l}-0.020 * * * \\
(0.006)\end{array}$ & $\begin{array}{l}-0.019 * * * \\
(0.006)\end{array}$ & $\begin{array}{l}-0.019 * * * \\
(0.006)\end{array}$ \\
\hline High experience & $\begin{array}{l}1.324 * * * \\
(0.027)\end{array}$ & $\begin{array}{l}1.715^{* * *} \\
(0.037)\end{array}$ & $\begin{array}{l}1.835^{* * *} \\
(0.039)\end{array}$ & $\begin{array}{l}0.369 * * * \\
(0.009)\end{array}$ & $\begin{array}{l}0.435^{* * *} \\
(0.010)\end{array}$ & $\begin{array}{l}0.447 * * * \\
(0.011)\end{array}$ \\
\hline Male doc. $\times$ High exp. & $\begin{array}{l}0.102 * * * \\
(0.037)\end{array}$ & $\begin{array}{l}0.087 * * \\
(0.036)\end{array}$ & $\begin{array}{l}0.089 * * \\
(0.036)\end{array}$ & $\begin{array}{l}0.041 * * * \\
(0.011)\end{array}$ & $\begin{array}{l}0.038 * * * \\
(0.011)\end{array}$ & $\begin{array}{l}0.039 * * * \\
(0.011)\end{array}$ \\
\hline Constant & $\begin{array}{l}1.838 * * * \\
(0.014)\end{array}$ & $\begin{array}{l}1.642 * * * \\
(0.019)\end{array}$ & $\begin{array}{l}1.582 * * * \\
(0.020)\end{array}$ & $\begin{array}{l}0.065^{* * *} \\
(0.004)\end{array}$ & $\begin{array}{l}0.033 * * * \\
(0.005)\end{array}$ & $\begin{array}{l}0.026 * * * \\
(0.006)\end{array}$ \\
\hline Patient's controls & No & Yes & Yes & No & Yes & Yes \\
\hline Doctor's controls & No & No & Yes & No & No & Yes \\
\hline Observations & 12512 & 12512 & 12512 & 12512 & 12512 & 12512 \\
\hline
\end{tabular}

Notes: The sample includes 3,128 participants; 1,561 are in the female-doctor treatment group while 1,567 are in the male-doctor treatment group. The number of observations is 12,512 because each participant ranks four doctors of the same gender but different castes (high or low) and experience levels (high or low). Reverse rank is five minus the rank the doctor receives. Ranked first is a dummy variable for whether the doctor is ranked the most preferred. Patient's controls include Hindu and the interaction between Hindu and the high experience dummy. Doctor's controls include doctor's caste (high or low), a dummy for 12 years of experience, and the interaction between each of the two controls and the high experience dummy. Robust standard errors are reported in parentheses. $* * * \mathrm{p}<0.01 ; * * \mathrm{p}<0.05 ;{ }^{*} \mathrm{p}<0.1$.

We can use the estimates for the most preferred doctor to help put the results in perspective. The estimates indicate that when patients are paying for health services in private practices or by booking for health services in the public system when the system is not constrained, nearly 90 percent of these patients would end up seeing the more experienced doctors. Among these experienced doctors seen by the majority of patients, male doctors are facing stronger demands. Female doctors only hold an advantage over inexperienced male doctors, especially in the first few years of practicing. As their experience grows, the advantage diminishes. It is thus not surprising that the earnings of male health professionals grow much faster than the earnings of female health professionals as their experience increases as we have found in Section 3.2. This lower age-earnings profile for female doctors may not only lead to greater labor market attrition, especially after marriage and childbirth, but may also discourage them from pursuing medicine in the first place, which in turn worsens the representation of female students in medical schools. 


\subsection{Caste discrimination and gender inequality}

We are interested in knowing whether the presence of caste discrimination worsens gender inequality among low-caste doctors. We first confirm in Figure 4 that there is evidence of caste discrimination. On average, high-caste doctors are more preferred than low-caste doctors for a given level of experience. These estimates are consistent with those reported in Islam et al. (2018).

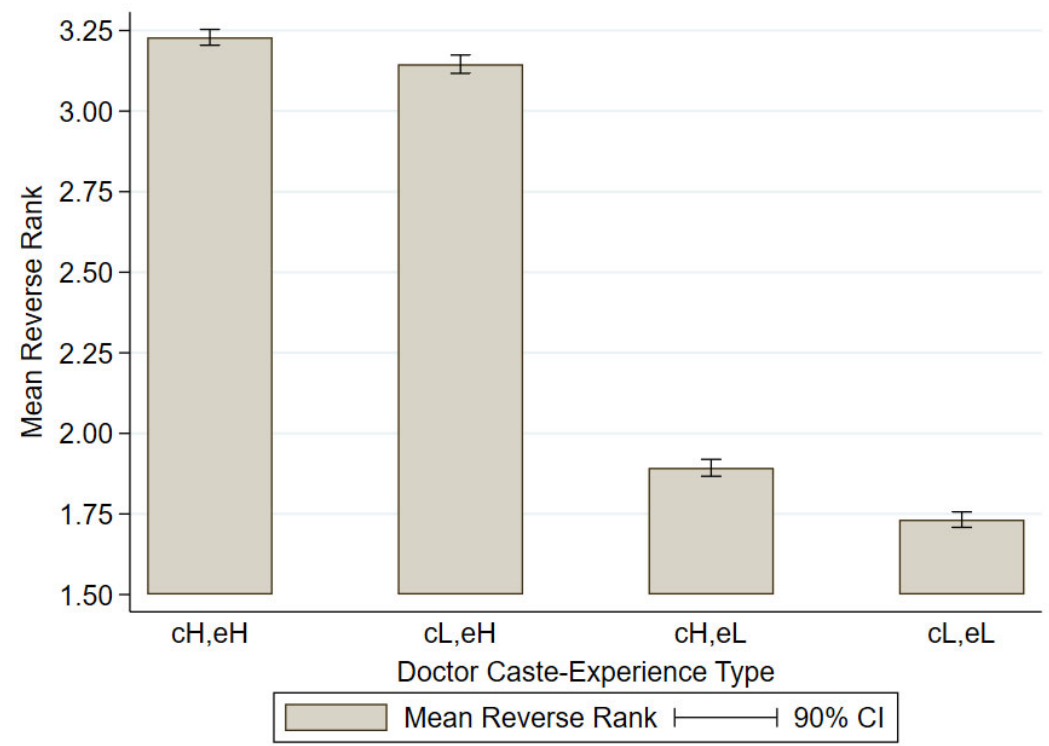

Figure 4. Evidence of caste-based discrimination.

Notes: Reverse rank is five minus the rank of a doctor receives from a participant. A doctor who receives a higher reverse rank is more preferred. $\mathrm{cH}, \mathrm{eH}=$ high-caste high-experience dctor; $\mathrm{cL}, \mathrm{eH}=$ low-caste high-experience doctor; $\mathrm{cH}, \mathrm{eL}=$ high-caste low-experience doctor; and $\mathrm{cL}, \mathrm{eL}=$ low-caste low-experience doctor. None of the $90 \%$ confidence intervals of a type of doctor contains the mean reverse rank of another type of doctor.

Figure 5 confirms Proposition 2 and Corollary 1 under caste discrimination. The experience level at which male doctors become more preferred than female doctors occur at a lower level of experience among low-caste doctors than among high-caste doctors. Among low-caste experienced doctors, female doctors are significantly less preferred than male doctors, whereas among low-caste less-experienced doctors, female doctors are marginally more preferred than male doctors. In contrast, the opposite is observed among high-caste doctors. Among highcaste experienced doctors, female doctors and male doctors are equally preferred, whereas among high-caste less-experienced doctors, female doctors are significantly more preferred than male doctors. Thus, gender inequality is worse among low-caste doctors who also suffer from caste discrimination. 


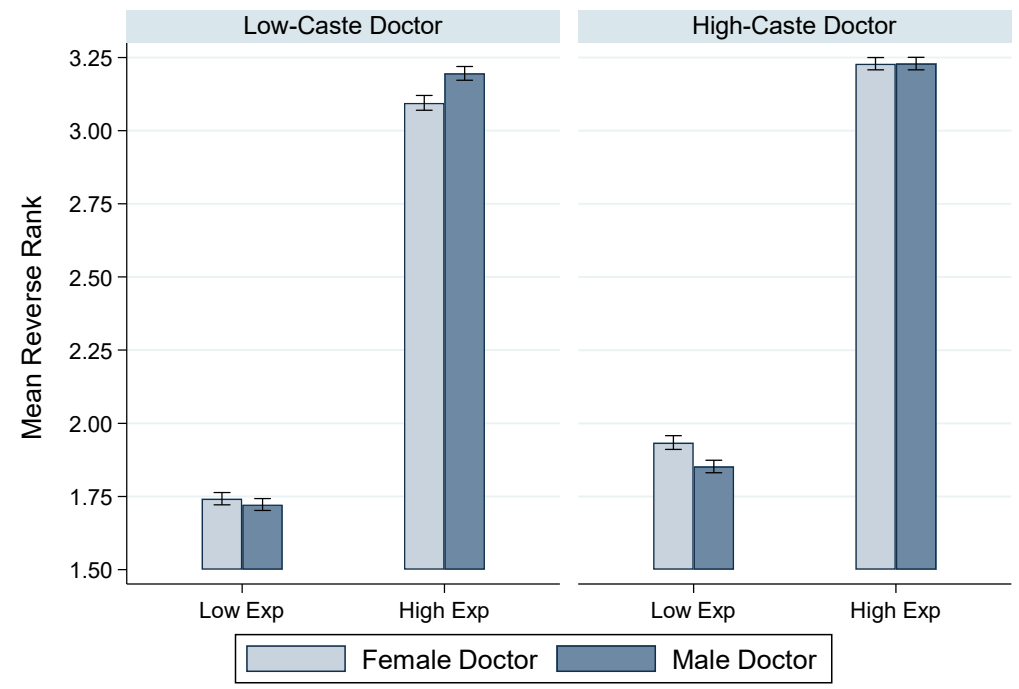

Figure 5. Statistical discrimination of doctors on the basis of gender by caste of doctor. Notes: Reverse rank is five minus the rank of a doctor receives from a participant. A doctor who receives a higher reverse rank is more preferred. Error bars represent mean \pm SEM.

Table 5 reports the regression estimates where the dependent variable is the reverse rank a doctor receives (panel A) and where the dependent variable is a dummy for whether a doctor is ranked first (panel B). Proposition 2 is evident in the statistically significant negative coefficient for the male doctor indicator among the high-caste doctor sample, while statistically not significant coefficient for the male doctor indicator among low-caste doctor sample. For example, in panel A, among high-caste doctors with four years of experience, male doctors receive a rank of 0.08 below female doctors. In contrast, among low-caste doctors with four years of experience, male doctors receive a statistically similar rank to female doctors. As experience grows, the reverse rank for low-caste male doctors grows much more than the reverse rank for low-caste female doctors. Similarly, as experience grows, the reverse rank for high-caste male doctors also grows much more than the reverse rank for high-caste female doctors. The main difference between low-caste male doctors and high-caste male doctors is that the return to experience is much stronger for the former. Over the range of experience levels in the experiment, there exists a range in which high-caste male doctors are statistically less preferred than high-caste female doctors. In comparison, no such range of experience is present for low-caste female doctors. The results imply that as doctors accumulate more experience, gender inequality becomes more severe among low-caste doctors. The results are similar when we examine whether a doctor is ranked the most preferred (panel B), but the 
estimates are generally noisier. Thus, Corollary 1 that gender inequality is worse among lower caste doctors is evident here.

Table 5

Gender gap in doctor preferences by experience and caste of doctor.

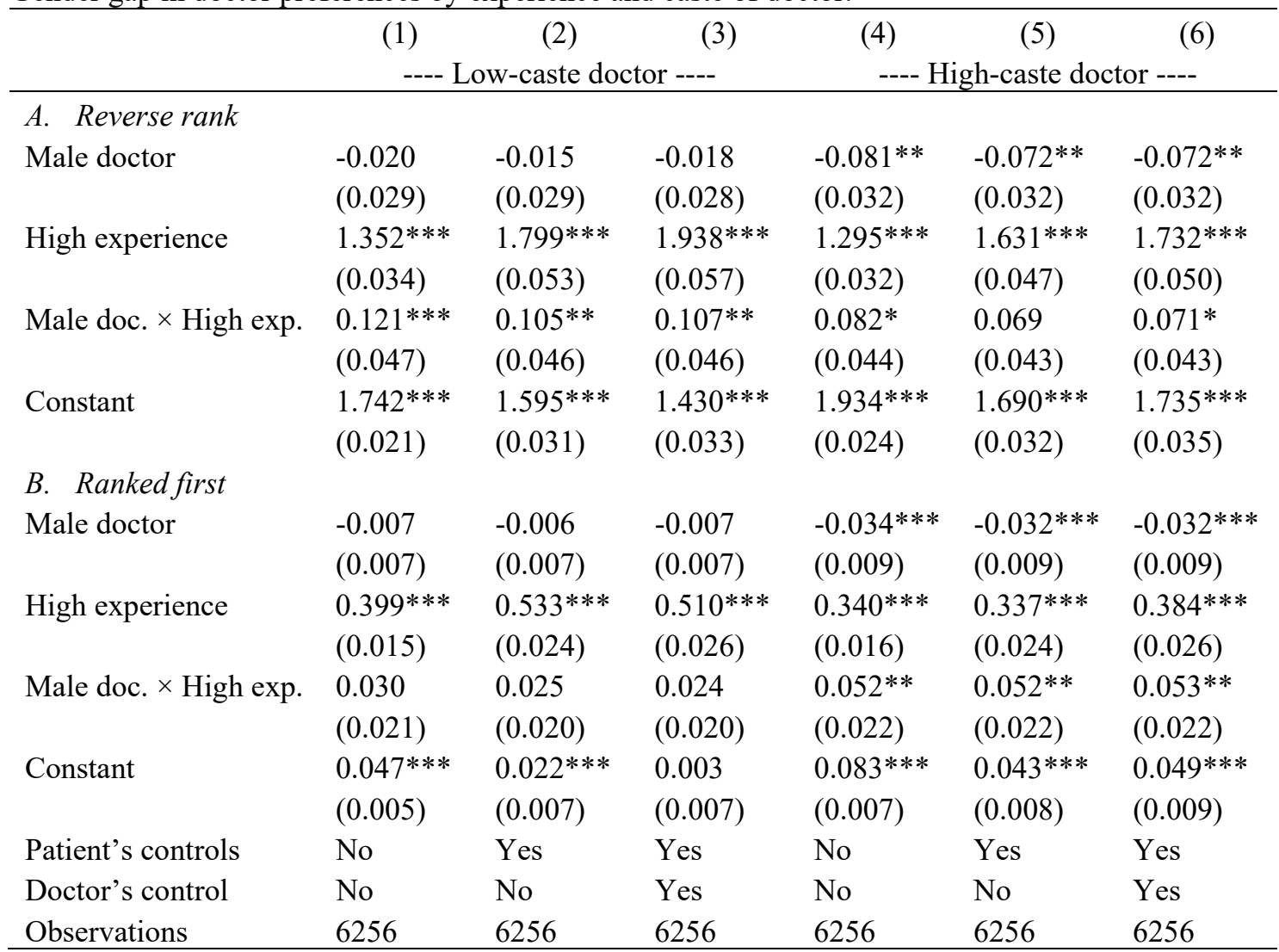

Notes: The sample includes 3,128 participants; 1,561 are in the female-doctor treatment group while 1,567 are in the male-doctor treatment group. The number of observations is 6,256 because each participant ranks two doctors of the same gender but different experience levels (high or low) from the same caste group. Reverse rank is five minus the rank the doctor receives. Ranked first is a dummy variable for whether the doctor is ranked the most preferred. Patient's controls include Hindu and the interaction between Hindu and the high experience dummy. Doctor's controls include a dummy for 12 years of experience and its interaction with the high experience dummy. Robust standard errors are reported in parentheses. ${ }^{* * *} \mathrm{p}<0.01 ;{ }^{* *} \mathrm{p}<0.05 ;{ }^{*} \mathrm{p}<0.1$.

In summary, the field experimental evidence is consistent with the theoretical prediction that gender inequality exacerbates among low-caste doctors when there is also caste discrimination against low-caste doctors. When patients statistically discriminate doctors based on gender, caste discrimination further worsens gender inequality among low-caste doctors. The estimates regarding gender differences by the experience and caste of doctor indicate that within each caste, the demand for male doctors grows relatively more than that for female doctors as they become more experienced. Since there is caste discrimination against low-caste doctors, the results mean that any relative disadvantage that low-caste female doctors suffer does not 
diminish with greater labor market experience, at least in the range of experience investigated in the experiment.

\subsection{The implication for overall gender inequality}

The evidence so far indicates that patients statistically discriminate doctors based on gender and that the presence of caste discrimination worsens gender inequality among low-caste doctors relative to gender inequality among high-caste doctors. In the field experiment patients are presented with the same number of low-caste and high-caste doctors with different years of experience as well as similar fractions of male and female doctors. However, the actual shares of doctors of different genders and caste groups in India are different. If doctors are predominantly and increasingly from a lower caste background, our results imply an overall increase in gender inequality as a result of this intersectionality in India.

We use several years of national employment survey from India to extrapolate how the increasing representation of low-caste individuals in medical professions may influence overall gender inequality among doctors. Figure 6 shows that it is increasingly less likely for health professionals who recently graduated from university to come from a high-caste background. The share was approximately 88 percent in 1999 but it fell to a bit below 50 percent by 2009 . These figures indicate that younger generations of health professionals are more likely to come from a lower caste background than older generations of health professionals. Given the trend in the growing share of lower caste health professionals, our findings here imply that gender inequality among health professionals is likely to worsen in India over time. 


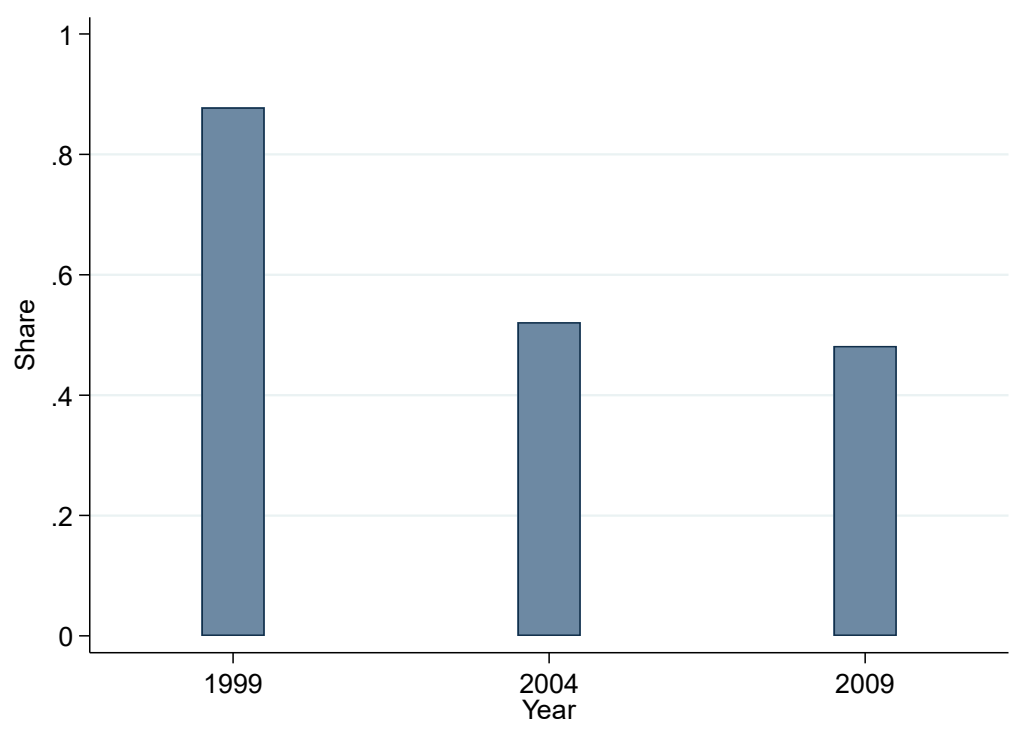

Figure 6. Share of young high-caste health professionals over time.

Note: Individuals aged 21 to 25 who listed occupation as a health professional and had graduated from university. Source: Authors' calculation based on data drawn from the 1999, 2004, and 2009 Employment Surveys (SocioEconomic Survey, Household Schedule 10: Employment and Unemployment) collected by the National Sample Survey Organization (NSSO). We obtained the data from Minnesota Population Center's (2020) Integrated Public Use Microdata Series.

\section{Conclusion}

In this paper, we show theoretically and empirically that when patients statistically discriminate doctors based on gender, while also discriminate doctors based on caste, gender inequality among low-caste doctors exacerbates with an increase in experience. Although our findings cannot rule out alternative mechanisms that are inconsistent with statistical discrimination, they imply that the intersectionality between gender and caste discrimination can exacerbate overall gender inequality among high-skilled workers in India given the increasing representation of low-caste workers in high-skilled occupations. The findings call for greater policy attention to individuals at the intersection of different discriminated groups.

The primary policy responses to address the underrepresentation of women and lower caste individuals in politics and governments in India have been the use of gender-based and castebased reservations. Although gender-based reservations for enrollments in STEM fields in higher educational institutions were introduced in recent years in a few Indian states, castebased reservations have been used in higher educational institutions for decades. These castebased reservations have undoubtedly led to improved representation of lower-caste individuals in a variety of high-skilled occupations, which have in turn increased their earnings (Bertrand 
et al., 2010). However, caste-based discrimination persists, raising the question of whether alternative approaches in the implementation of AA other than reservations should be considered (Islam et al., 2018). The seminal work of Coate and Loury (1993) on AA policy suggests that when individuals are statistical discriminators, quotas can lead to the patronizing equilibrium where the intended beneficiary group is not benefitted.

An alternative AA policy to reservations can potentially be to allocate additional educational resources to improve the preparation of students from underrepresented groups for college admissions. By improving their preparation for college admissions without altering the admission standards, such an alternative form of AA may reduce negative stereotype people may hold against underrepresented individuals and consequently the discrimination they suffer. Given the implications of the intersectionality of gender and caste discrimination on gender inequality among high-skilled workers, it is worthwhile to consider this alternative form of AA. Such an alternative form of AA has the potential to improve representation without reinforcing statistical discrimination against women and low-caste individuals. The increased representation and reduced discrimination against women and low-caste individuals in various high-skilled occupations should ultimately lead to increased market competition and higher overall quality of goods and services. 


\section{References}

Abbink, K., Islam, A. and Nguyen, C., 2020. Whose voice matters? An experimental examination of gender bias in intra-household decision-making. Journal of Economic Behavior \& Organization. 176, 337-352.

Afridi, F., Iversen, V., Sharan, M. R., 2017. Women political leaders, corruption, and learning: Evidence from a large public program in India. Economic Development and Cultural Change. 66 (1), 1-30.

Aigner, D. J., Cain, G. G., 1977. Statistical Theories of Discrimination in Labor Markets. Industrial and Labor Relations Review. 30 (2), 175-187.

Arcidiacono, P., Lovenheim, M., 2016. Affirmative action and the quality-fit trade-off. Journal of Economic Literature. 54 (1), 3-51.

Arrow, K. J., 1973. The theory of discrimination in O. Ashenfelter, A. Rees (Ed.), Discrimination in labor markets. Princeton University Press. 3-33.

Bagde, S., Epple, D., Taylor, L., 2016. Does affirmative action work? Caste, gender, college quality, and academic success in India. American Economic Review. 106 (6), 1495-1521.

Balafoutas, L., Davis, B.J., Sutter, M., 2016. Affirmative action or just discrimination? A study on the endogenous emergence of quotas. Journal of Economic Behavior \& Organization. 127, 87-98.

Banerjee, A., Bertrand, M., Datta, S., Mullainathan, S., 2009. Labor market discrimination in Delhi: Evidence from a field experiment. Journal of comparative Economics. 37 (1), 14-27.

Banerjee, A., Duflo, E., Ghatak, M., Lafortune, J., 2013. Marry for what? Caste and mate selection in modern India. American Economic Journal: Microeconomics. 5 (2), 33-72.

Beaman, L., Duflo, E., Pande, R., Topalova, P., 2012. Female leadership raises aspirations and educational attainment for girls: A policy experiment in India. Science. 335 (6068), 582586.

Becker, G.S., 1957. The Economics of Discrimination. Chicago University Press.

Begum, L., Grossman, P.J., Islam, A., 2018. Gender bias in parental attitude: An experimental approach. Demography. 55 (5), 1641-1662.

Bertrand, M., Hanna, R., Mullainathan, S., 2010. Affirmative action in education: Evidence from engineering college admissions in India. Journal of Public Economics. 94 (1-2), 1629.

Bhalotra, S., Valente, C., Van Soest, A., 2010. The puzzle of Muslim advantage in child survival in India. Journal of Health Economics. 29 (2), 191-204.

Bohren, J.A., Imas, A., Rosenberg, M., 2019. The dynamics of discrimination: Theory and evidence. American Economic Review. 109 (10), 3395-3436.

Borooah, V.K., Iyer, S., 2005. Vidya, Veda, and Varna: The influence of religion and caste on education in rural India. The Journal of Development Studies. 41 (8), 1369-1404.

Cassan, G., 2019. Affirmative action, education and gender: Evidence from India. Journal of Development Economics. 136, 51-70.

Castillo, M., Petrie, R., Torero, M., Vesterlund, L., 2013. Gender differences in bargaining outcomes: A field experiment on discrimination. Journal of Public Economics. 99, 35-48.

Chakraborty, S., 2020. Gender Wage Differential in Public and Private Sectors in India. The Indian Journal of Labour Economics. 63 (3), 765-780.

Chattopadhyay, R., Duflo, E., 2004. Women as policy makers: Evidence from a randomized policy experiment in India. Econometrica. 72 (5), 1409-1443.

Chaudhury, A.R., Sinha, M., 2020. Does Education Produce Identical Labour Market Outcomes for All? A Study on India. Margin: The Journal of Applied Economic Research. 14 (3), 309-331.

Clots-Figueras, I., 2012. Are female leaders good for education? Evidence from India. American Economic Journal: Applied Economics. 4 (1), 212-44. 
Coate, S., Loury, G.C., 1993. Will affirmative-action policies eliminate negative stereotypes? The American Economic Review. 1220-1240.

Conrad, C., 2001. Racial trends in labor market access and wages: Women. America becoming: racial trends and their consequences. 2, 124-51.

Crenshaw, K., 1989. Demarginalizing the intersection of race and sex: A Black feminist critique of antidiscrimination doctrine, feminist theory and antiracist politics. University of Chicago Legal Forum. 139-167.

Crenshaw, K., 1991. Mapping the margins: Intersectionality, identity politics, and violence against women of color. Stanford Law Review. 43 (6), 1241-1299.

Delavande, A., Zafar, B., 2013. Gender discrimination and social identity: Experimental evidence from Urban Pakistan. Federal Reserve Bank of New York Staff Report No. 593.

Deshpande, A., 2019. Double jeopardy? Stigma of identity and affirmative action. The Review of Black Political Economy. 46 (1), 38-64.

Deshpande, A., 2013. Social justice through affirmative action in India: An assessment. In Capitalism on Trial. Edward Elgar Publishing.

Ewens, M., Tomlin, B., Wang, L.C., 2014. Statistical discrimination or prejudice? A large sample field experiment. Review of Economics and Statistics. 96 (1), 119-134.

Fins, A., 2019. National snapshot: Poverty among women and families. National Women's Law Center:

Available at: https://nwlc.org/wp-content/uploads/2019/10/PovertySnapshot2019-2.pdf.

Gangadharan, L., Jain, T., Maitra, P., Vecci, J., 2016. Social identity and governance: The behavioral response to female leaders. European Economic Review. 90, 302-325.

Islam, A., Pakrashi, D., Wang, L.C. and Zenou, Y., 2018. Determining the Extent of Statistical Discrimination: Evidence from a field experiment in India. CEPR Discussion Paper No. 12955.

Islam, A., Pakrashi, D., Vlassopoulos, M., Wang, L.C., 2021. Stigma and misconceptions in the time of the COVID-19 pandemic: A field experiment in India. Social Science \& Medicine. 278, 113966.

Karekurve-Ramachandra, V., Lee, A., 2020. Do gender quotas hurt less privileged groups? Evidence from India. American Journal of Political Science. 64 (4), 757-772.

Kumar, R., 2020. Why states are eagerly giving job quota to women? It's the game of votes, News18, 17 October. Available at: https:/www.news18.com/news/opinion/why-states-areeagerly-giving-job-quota-to-women-its-the-game-of-votes-2974910.html.

Lahoti, R., Swaminathan, H., 2016. Economic development and women's labor force participation in India. Feminist Economics. 22 (2), 168-195.

Leibbrandt, A., Wang, L.C., Foo, C., 2018. Gender quotas, competitions, and peer review: Experimental evidence on the backlash against women. Management Science. 64(8), 35013516.

Lesner, R.V., 2018. Testing for statistical discrimination based on gender. Labour. 32 (2), 141181.

Longhi, S., 2020. Racial wage differentials in developed countries. IZA World of Labor. 365.

Madheswaran, S., Attewell, P., 2007. Caste discrimination in the Indian urban labour market: Evidence from the National Sample Survey. Economic and Political Weekly. 42 (41), 41464153.

Maitra, P., Rosenblum, D., 2021. Upstream effects of female political reservations. European Journal of Political Economy. 102061.

Minnesota Population Center. Integrated Public Use Microdata Series, International: Version 7.3 [dataset]. Minneapolis, MN: IPUMS, 2020. https://doi.org/10.18128/D020.V7.3

Oostendorp, R. H., 2009. Globalization and the gender wage gap. World Bank Economic Review. 23 (1), 141-161. 
Phelps, E. S., 1972. The statistical theory of racism and sexism. American Economic Review. 62 (4), 659-661.

Sharma, K., 2020. IITs take women's quota to $20 \%$ as govt pushes gender balance in tech education, The Print, 17 March. Available at: https://theprint.in/india/education/iits-takewomens-quota-to-20-as-govt-pushes-gender-balance-in-tech-education/379395/

Siddique, Z., 2011. Evidence on caste-based discrimination. Labour Economics. 18, S146S159.

Thorat, S., Attewell, P., 2007. Legacy of social exclusion: A correspondence study of job discrimination in India. Economic and Political Weekly. 42 (41), 4141-4145.

UNDP (United Nations Development Programme), 2019. Human development report 2019. Beyond income, beyond averages, beyond today: Inequalities in human development in the 21 st century. New York: United Nations development programme.

Varma, R., 2018. US science and engineering workforce: Underrepresentation of women and minorities. American Behavioral Scientist. 62 (5), 692-697.

Wankhede, G. G., 2016. Higher education and the scheduled castes in Maharashtra. Economic and Political Weekly. 51 (6), 83-86.

World Bank, 2016. Uttar Pradesh - Poverty, Growth and Inequality (English). India state briefs. Washington D.C.: World Bank Group. 


\section{Online Appendix}

\section{A.1. Taste-based gender discrimination}

We present a simple additively separable utility function for an average patient to illustrate the possible rankings under taste-based gender discrimination when the experience of a doctor signals better quality of healthcare. We note that these rankings are true for any utility function that satisfies the five axioms of consumer choice: completeness, transitivity, continuity, strict monotonicity, and strict convexity.

The utility function for a patient ranking a doctor of gender $s=s_{f}, s_{m}$ is given by:

$$
U(\mathrm{~s}, q)=q(e)-1_{\theta_{f}}
$$

where $1_{\theta_{f}}=\theta_{f}>0$ if the doctor is female and zero otherwise. The indicator $1_{\theta_{f}}$ indicates whether the patient has any distaste against female doctors. This distaste parameter $\theta_{f}$ captures Becker's (1957) notion of taste-based discrimination where the discriminator (i.e., a sexist) suffers a psychic cost when interacting with a female doctor. As in the statistical discrimination model, we assume that $q^{\prime}(e)>0$ (i.e., doctors with more years of experience provide better quality health service).

An average sexist patient's problem is to rank four doctors, two males $\left(s_{m}\right)$ and two females $\left(s_{f}\right)$. Two of the four doctors, one from each of the gender group, have a low level of experience $\left(e_{L}\right)$. The remaining two doctors are equally experienced and have a high level of experience $\left(e_{H}\right)$. The possible rankings compatible with (A.1) are:

$$
\begin{aligned}
& s_{m} e_{H}>s_{m} e_{L}>s_{f} e_{H}>s_{f} e_{L} \\
& s_{m} e_{H}>s_{f} e_{H}>s_{m} e_{L}>s_{f} e_{L}
\end{aligned}
$$

In the first ranking, we need to give the condition for which $s_{m} e_{L}>s_{f} e_{H}$ (the other inequalities are always true by definition since $e_{H}>e_{L}$ ). The condition is:

$$
\theta_{f}>q\left(e_{H}\right)-q\left(e_{L}\right)
$$

In the second ranking, we need to give condition for which $s_{f} e_{H}>s_{m} e_{L}$ (the other inequalities are always true by definition since $e_{H}>e_{L}$ ). The condition is:

$$
\theta_{f}<q\left(e_{H}\right)-q\left(e_{L}\right)
$$

Proposition 1 in the main text indicates that under statistical discrimination, an average patient can have the following ranking which is incompatible with (A.1):

$$
s_{m} e_{H}>s_{f} e_{H}>s_{f} e_{L}>s_{m} e_{L}
$$

Thus, taste-based discrimination against female doctors cannot generate the prediction given by Proposition 1 . 